University of Pennsylvania Carey Law School

Penn Law: Legal Scholarship Repository

Faculty Scholarship at Penn Law

9-12-2007

\title{
Constructing the License to Operate: Internal Factors and their Influence on Corporate Environmental Decisions
}

Jennifer A. Howard-Grenville

Boston University Department of Organizational Behavior

Jennifer Nash

Harvard University John F. Kennedy School of Government

Cary Coglianese

University of Pennsylvania Carey Law School

Follow this and additional works at: https://scholarship.law.upenn.edu/faculty_scholarship

Part of the Administrative Law Commons, Business Administration, Management, and Operations Commons, Environmental Law Commons, and the Organizations Law Commons

\section{Repository Citation}

Howard-Grenville, Jennifer A.; Nash, Jennifer; and Coglianese, Cary, "Constructing the License to Operate: Internal Factors and their Influence on Corporate Environmental Decisions" (2007). Faculty Scholarship at Penn Law. 101.

https://scholarship.law.upenn.edu/faculty_scholarship/101

This Article is brought to you for free and open access by Penn Law: Legal Scholarship Repository. It has been accepted for inclusion in Faculty Scholarship at Penn Law by an authorized administrator of Penn Law: Legal Scholarship Repository. For more information, please contact PennlawIR@law.upenn.edu. 


\title{
Constructing the License to Operate: Internal Factors and their Influence on Corporate Environmental Decisions
}

\author{
Jennifer Howard-Grenville \\ University of Oregon Lundquist College of Business \\ Jennifer Nash \\ Harvard University Kennedy School of Government \\ Cary Coglianese \\ University of Pennsylvania Law School
}

September 12, 2007

We thank Raymond Paquin and Gopal Raman for valuable research assistance, as well as Lori Snyder Bennear. We also thank Dan Fiorino, Fiona Haines, Andrew Hoffman, Robert Kagan, Jane Nelson, John Ruggie, Colin Scott, participants at the 2006 Law \& Society Association annual meeting and the 2003 Greening of Industry Network conference, and our anonymous reviewers for their comments. Research was made possible with support from the U.S. Environmental Protection Agency Office of Policy, Economics, and Innovation, Grant No. R83056701, and the Corporate Social Responsibility Initiative, John F. Kennedy School of Government, Harvard University. This article represents the authors' views, not necessarily those of the research sponsors. A version of this article is forthcoming in Law \& Policy (2008). 


\section{Constructing the License to Operate: Internal Factors and their Influence on Corporate Environmental Decisions}

Voluntary programs intended to improve corporate environmental practices have proliferated in recent years. Why some businesses choose to participate in such voluntary programs, while others do not, remains an open question. Recent work suggests that companies' environmental practices, including their decisions to participate in voluntary programs, are shaped by a license to operate comprised of social, regulatory, and economic pressures. Although these external factors do matter, by themselves they only partially explain business decision making, since facilities subject to similar external factors often behave differently. In this article, we draw from organizational theory to explain why we would expect a company's license to operate to be ultimately constructed by internal factors, such as managerial incentives, organizational culture, and organizational identity, as these shape both interpretations of the external pressures and organizational responses to them. Using qualitative data from an exploratory study of matched facilities that reached different decisions about participating in a prominent voluntary environmental program, we then report evidence indicative of the role of these internal factors in shaping facilities' environmental decisions. Finally, we offer suggestions for future research that could further develop understanding of how internal organizational characteristics influence environmental management decisions, including those concerning participation in voluntary programs. 


\section{Constructing the License to Operate: Internal Factors and their Influence on Corporate Environmental Decisions}

What determines the environmental practices of individual companies and facilities? In particular, what leads some businesses to take actions that go beyond compliance with environmental regulation? Despite more than two decades of research devoted to these questions, scholars "still know little about why individual corporations behave the way they do in the environmental context, about why some companies, but not others, choose to move beyond compliance, or what motivates them to do so" (Gunningham et al. 2003: 135).

Firms' environmental practices are generally thought to result from a constellation of factors including regulatory requirements, competitive and economic pressures, evolving social demands and institutional norms, and technological innovation and adoption (Porter \& van der Linde 1995; Hoffman 1997; Reinhardt 2000; Vogel 2005). Increasingly, scholars argue that companies experience possibly unique constellations of external pressures shaped by their community, location, economic sector, and interactions with critical external actors (Gunningham et al. 2003; Delmas \& Toffel 2005). Such an approach, drawing attention to each firm’s or facility’s “license to operate” (Gunningham et al. 2003), begins to explain differences that have been observed in environmental management practices within and between industries (Prakash 2000; Gunningham \& Kagan 2005).

These explanations are incomplete, however, because they fail to take account of the fact that different firms, operating under similar regulatory, competitive, and social pressures, can develop starkly different environmental management approaches. Consider an example. Two competing manufacturing facilities located only miles apart produce the same specialized industrial component for the same set of customers. Both employ the same number of people and 
both are among the largest employers in their mostly rural communities. In the not-so-distant past, both had been implicated in significant pollution problems in their communities, but both had more recently implemented sophisticated environmental management systems and had stayed in compliance with state and federal environmental regulations. Although similar in their customer base, line of business, community location, and overall environmental performance, these two facilities have made completely different choices about whether to participate in a federally sponsored voluntary environmental program. Why? In this article, we explore the choices made by these two companies, and other similarly matched pairs of facilities, by drawing attention to the internal factors that influence how managers interpret external conditions and act upon them.

Even when external factors clearly influence companies' actions on environmental issues, internal factors shape whether and how the external conditions are regarded as problems for the company in the first place, and internal factors also influence what solutions are deemed appropriate for addressing the identified problems (Lyles \& Mitroff 1980; Dutton \& Ashford 1993). "Problems" do not simply drop from the sky; they are formulated by managers as they selectively attend to cues from both insiders and outsiders (Lyles \& Mitroff 1980). Individual, group, and organizational level factors have all been shown to contribute to business decision making, suggesting that "managers are guided in their choices as to what is important and why it is important by the interaction of the categories of issues they confront, their own experiences, and the natures of the teams and organization to which they belong” (Thomas, Shankster, \& Mathieu 1994).

In this article, we connect general insights about organizations to an emerging body of work that draws attention to the influence of internal factors specifically on businesses' regulatory 
behavior (Haines 1997; Barnes \& Burke 2006). As others have acknowledged, firms’ decisions about their environmental operations can be affected by managerial perceptions (Andersson \& Bateman 2000; Sharma 2000; Gunningham et al. 2003; Vandenbergh 2003), organizational culture (Forbes \& Jermier 2002; Howard-Grenville 2006, 2007), and organizational structure (Delmas \& Toffel 2005). Plant-level variables (such as size or age of facility) have been found to be better predictors of regulatory compliance behavior than corporate-level variables, suggesting that plant management plays an important role in determining whether and how a plant will comply or go beyond compliance (Gray \& Shadbegian 2005). Connecting the behavioral determinants of internal plant-level decision making with observed environmental practices presents a key opportunity to understand better the processes and predictors of firm's and facilities' environmental management choices. Although it may seem readily apparent that both internal and external factors enter in to these choices, the internal factors have received markedly less systematic, empirical attention than have the external ones. Our intention in this article is to elaborate theoretically and empirically key organizational and individual factors that contribute to the construction of the license to operate and affect plant-level environmental decision making.

We begin this article by briefly considering the literature on the determinants of beyondcompliance environmental practice and then proceed to articulate what we mean by the internal construction of the license to operate by drawing on selected insights from organizational theory. Next, we identify from prior work five key internal factors - managerial incentives, organizational culture, organizational identity, organizational self-monitoring, and personal affiliations and commitments -and explain how each could importantly shape environmental decision making. Following this, we report on our study of ten closely matched facilities. Five of 
these facilities had chosen to participate in a voluntary environmental program, the United States Environmental Protection Agency’s (EPA) National Environmental Performance Track (NEPT), which offers recognition, networking opportunities, and certain types of administrative and regulatory flexibility to those that meet entry requirements. The other five matched facilities in our study had chosen not to participate in NEPT but share similar industrial processes, are of comparable size and output, have roughly equivalent environmental performance and compliance records, are subject to similar environmental regulatory permit requirements, and operate in demographically comparable locations in a single region. Interview data from facility managers show that at least three of the factors we explicate - the company's identity, managerial incentive systems, and willingness to engage external constituencies ("self monitoring") - differed between participating facilities and their matches, suggesting that these factors can indeed help explain environmental management choices. We conclude with implications and directions for future research that can extend our understanding of how companies' licenses to operate are constructed by internal factors interacting with external ones.

\section{What Shapes Beyond-Compliance Environmental Practice?}

Understanding why and how firms adopt beyond-compliance environmental practices is a critically important question for both scholars and policy makers. ${ }^{1}$ Researchers have advanced several specific reasons for firms’ participation in voluntary environmental programs, a key form of beyond-compliance behavior. Participation in a voluntary program may provide financial savings (Maxwell \& Decker 1998) or competitive advantage (Arora \& Cason 1996; Lyon \& Maxwell 1999), enable access to technical assistance (Khanna 2001; Delmas \& Keller 2005), help firms pre-empt or weaken regulations (Segerson \& Miceli 1998; Lyon \& Maxwell 2002; Johnston 2006), or shape future regulations (Delmas \& Terlaak 2001). Further, participation may create an image of environmental friendliness for customers, suppliers, employees, or the public 
(Khanna 2001; Potoski \& Prakash 2002), and demonstrate firms’ responsiveness to community and employee concerns (Henriques \& Sadorsky 1996; Blackman \& Bannister 1998; Gunningham et al. 2005).

These benefits, however, may be contingent upon a number of factors including the firm's competitive environment, exposure to regulatory or technological change, and the actions or demands of customers, investors, and community groups (Arora \& Cason 1996; Reinhardt 2000; Vogel 2005). Further, there are a number of potential costs associated with participation in voluntary programs, including: (a) increased scrutiny by regulators, the news media, or the surrounding community; (b) concern about maintaining confidentiality of production-related information; and (c) direct management time and resource commitment (Delmas \& Terlaak 2001). As a result, voluntary programs may prove attractive or unattractive to firms for a variety of reasons that are not necessarily anticipated by those who initiate the programs. Indeed, some empirical studies find that firms with relatively poor environmental records and a history of large toxic releases relative to their peers are sometimes more likely to participate in voluntary programs (Arora \& Cason 1996; King \& Lenox 2000), suggesting that the desire for an image of strong environmental performance, not the more tangible financial or technological benefits, may motivate firms' decisions to join. In the literature on corporate environmental management, the relatively simple notion that companies evolve through stages of increasingly advanced environmental practice (Hunt \& Auster 1990; Roome 1992) in response to demands from regulators, customers, and financial markets (Gladwin et al. 1995; Shrivastava 1995; Kleindorfer 2006) has now largely been replaced by a more nuanced view that acknowledges external contingencies that make the adoption of certain environmental practices more or less attractive 
for certain firms (Esty \& Porter 1998; Christmann 2000; Reinhardt 2000; Aragon-Correa \& Sharma 2003).

\section{The License to Operate}

Increasingly, corporate environmental practices are seen as the result of multiple, possibly firm-specific, drivers that interact with each other, including those originating in regulatory, international, resource, and social domains as well as in the marketplace (Hoffman 2000). One way of conceptualizing these myriad pressures on a firm is as a "license to operate.” This label has been widely used by companies, analysts, journalists, and scholars to refer to the idea that industrial facilities must comply with tacit expectations of regulators, local communities, and the public in order to continue operations (Gunningham et al. 2003, 2004; Howard-Grenville 2005). Some have noted, importantly, that these aspects of the license to operate are not simply imposed on a firm; they are at least partially subject to negotiation and revision by the firm's own actions (Gunningham et al. 2003). This view accords with recent work indicating that companies and the organizations they interact with jointly construct norms of legal compliance and standards for appropriate business conduct (Edelman, Uggen, \& Erlanger 1999; Hoffman 1999).

\section{Internal Factors}

Relative to the external factors that influence environmental management practice, internal factors have been understudied in the literature on voluntary corporate behavior. An accumulation of recent empirical work, however, suggests that internal factors matter. Managers' commitment, perceptions, and leadership (Andersson \& Bateman 2000; Egri \& Herman 2000; Sharma 2000; Bansal 2003), organizational culture and subcultures (Forbes \& Jermier 2002; Howard-Grenville 2006; Howard-Grenville 2007), and different organizational structures (Delmas \& Toffel 2005) have all been found to influence the environmental practices adopted by firms. Others have argued that broader constructs of managerial commitment (Coglianese \& 
Nash 2001) or environmental management style (Gunningham et al. 2003) critically shape environmental practice and performance. These constructs may include personal attitudes towards environmental problems as well as individual orientations that are shaped by and help shape the organization's culture and leadership (Vandenbergh 2003).

Missing from much of this work on the internal influences of environmental practice is a theoretical underpinning grounded in the literature on organizational behavior. Also missing are empirical studies that control for external factors to enable a clear comparison of internal factors across companies. Without these, we are left with at best a partial sense of where a particular environmental management style comes from, why one style is distinct from another, and whether a particular style will tend to endure or change over time (Howard-Grenville 2005). Indeed, without refinement and theoretical anchoring, constructs like management style or commitment risk becoming catch-all categories for all that remains unexplainable once external factors have been accounted for.

To address these needs, we draw from organizational theory specific internal factors that can be expected to contribute to corporate environmental practices. These factors generally have two effects: first, they shape whether and how members of a firm or facility interpret external regulatory, social, and economic conditions as problems in the first place, and, second, they influence how these members choose to solve the selected problems (see Figure 1). The first effect, known as “problem setting” (Schön 1983: 40), occurs when organizational structures, cultures, and subcultures channel and direct the attention of members to particular issues and orient them to specific goals (Simon 1947; Van Maanen \& Barley 1984; Schein 1996; Ocasio 1997; Howard-Grenville 2006). Individuals can be active participants in the formulation of problems from nascent issues, and their positions in formal and informal structures of power 
contribute to whose interpretations have influence within a given company. Given this, it should come as no surprise that companies and individuals interpret similar environmental pressures quite differently; in other words, they "set up” different problems to solve based on the same external data.

Figure 1 about here

Once problems are set, internal factors also shape how they are solved. Organizational structures, cultures, and systems of managerial incentives compel the use of certain favored “strategies for action” within a firm (Swidler 1986; Schein 1996; Howard-Grenville \& Hoffman 2003). When groups or individuals within an organization approach a given type of problem, they set about solving it using the knowledge, skills, routines, and resources that they possess and value. Of course, within any organization, different groups possess different types of knowledge, skill, and resources, and hold different interests and power (Carlile 2002), suggesting that the strategy for action ultimately adopted may represent the outcome of internal negotiation (Howard-Grenville 2006). Nonetheless, internal factors can differently influence the actions taken by organizations, even if they set themselves similar problems. Indeed, valued strategies for action tend to shape recursively the problems that firms' members set for themselves as they attend more closely to the problems that their strategies are most suited to attain (Swidler 1986).

Although problem setting and strategies for action may well be closely interrelated in practice, it is analytically helpful to separate them in order to understand, respectively, how internal factors shape the interpretation of external conditions and how internal factors lead to the development of solutions to address identified problems. Behavior within any company is a 
function of a complex set of incentives, some that are largely independent of any given change in external environmental issues or indeed any other external issue. To explain further what can make problem setting and strategies for action differ between otherwise similar firms, we outline five key internal factors that, at a minimum, we would expect to contribute to the construction of a company's license to operate: managerial incentives, organizational culture, organizational identity, organizational self-monitoring, and personal commitments and affiliations. Each of these internal factors is summarized in Table 1 and described below. Table 1 also notes several sources of evidence that may be used to understand whether and how each factor shows up in shaping problem setting and solving within a firm or facility.

\section{Table 1 about here}

Managerial Incentives. Managerial incentives include the formal and informal inducements that might encourage or dissuade a manager from taking some form of beyond-compliance behavior, like choosing to participate in a voluntary program. Managerial incentives stem from the company's formal structure, which establishes channels of communication and influence as well as authorizes certain reward systems. Of course, a company’s "informal” structure is at least as important in shaping managerial incentives as is its formal structure. Informal structure is associated with the actual interactions and expectations operating within a company, capturing how power is exercised and how social networks shape the flow of information (Krackhardt \& Hanson 1993). Both formal and informal structures influence who makes decisions, how decisions are made, and the degree of autonomy individual facilities and managers hold in decision making. For example, an environmental manager at a facility who reports directly to her 
plant manager may receive greater attention to and support for environmental issues than a facility manager reporting to a centralized, corporate-level environment, health, and safety unit (Russo \& Harrison 2005). When the overall manager of a facility is formally accountable for environmental management, the facility's environmental manager may be much more important to the facility’s communication networks and decision making processes. In such a situation, the environmental manager may well be more willing to initiate actions that she believes would improve the facility’s environmental reputation or performance. The most straightforward incentive for many managers, of course, is in the form of compensation. Here empirical research has shown that tying a portion of plant managers' compensation to environmental performance has a small positive effect on such performance (Russo \& Harrison 2005).

Formal and informal structures may have an independent effect on managers' actions, but they also can shape managers’ perceptions of the issues themselves. For example, formal organizational structures establish which groups or departments interface with which external groups (Lawrence \& Lorsch 1967), influencing who environmental managers come into contact with and whose concerns they hear. For example, with today’s environmental concerns extending far beyond those associated with production operations to encompass product lifecycle and many other concerns, managers in sales and marketing, finance, or strategic positions may be just as likely to encounter and interpret environmental issues as those in production functions. The degree of cross-functional coordination and control - structural and otherwise - within a company influences lateral and vertical information flows and hence awareness of environmental issues (Sharma et al. 1999). Clearly, those who are unaware of potential issues due to organizational arrangements will have little incentive to take action on them. 
Organizational Culture. An organization's culture can also affect managerial incentives, but more broadly it influences how problems are set and how they are acted upon. Organization culture is regarded by many scholars as a system of meanings that operate within an organization and that shape its members' daily actions (Gregory 1983; Smircich 1983; Meyerson \& Martin 1987; Schein 1992). Importantly, culture is not entirely negotiable (Douglas 1978); it is something an organization "is" rather than something that it "has" (Smircich 1983: 342). In other words, culture change cannot be so simple as changing a company's mission and values statements, or adopting a new program, for culture is embedded in the everyday actions that people take throughout the company. Whereas formal structures delineate who does what in an organization, culture influences how it is done and many of the cultural norms operating in organizations are tacit. For example, are decisions only taken when "hard" data are persuasively presented? Is consensus required for decisions to be made, or are individuals encouraged and trusted to pursue innovative approaches on their own? Does the organization prefer "homegrown" solutions or is it open to new ideas from outsiders with different expertise and perspectives? Is risk-taking behavior discouraged or rewarded? These are all aspects of an organization's culture that can both influence how people regard external pressures and information, as well as how they act when faced with problems.

For example, NASA's actions during both the Challenger and Columbia space shuttle tragedies have been attributed to cultural factors (Vaughn 1996; Roberto et al. 2006). In each case, incomplete evidence hinting at the eventual technical causes of failure was held by engineers who were at relatively low levels of their organizations. A culture characterized by a reliance on hard data, and the need to meet a substantial burden of proof in order to unseat prior conclusions about safety and risk, made it difficult for these engineers to advance their concerns. 
As one Columbia investigation board member noted, a cultural norm around decision making was "prove to me that it's wrong, and if you prove to me that there is something wrong, then I'll go look at it” (Roberto et al. 2006: 110). NASA's culture strongly influenced which events and anomalies were labeled "problems" and, once labeled, how they were acted upon. More generally, culture helps explain a variety of organizational actions, whether they are prompted by internal or external events (Allison \& Zelikow 1999; Snook 2000; Howard-Grenville 2007).

Organizational Identity. Whereas organizational culture refers to the patterns of day-to-day actions within an organization, organizational identity refers to an overarching sense among members of "what the organization stands for and where it intends to go" (Albert, et al. 2000). Organizational identity is defined as that which is central, enduring, and distinctive about an organization as perceived by its members (Albert \& Whetten 1985). In contrast to culture, which refers to patterns of meaning arising from day-to-day interactions within a company, identity emerges through interactions with the outside world (Hatch \& Schulz 2002). Critical events can feed into a revision of a company's identity and contribute to it on an ongoing basis. For example, the Brent Spar incident for Royal Dutch Shell triggered adjustments in employees’ impressions of the company and strongly influenced its subsequent efforts to shape its identity proactively (Hatch \& Schulz 2002).

Organizational identity shapes how managers view the work of their company or facility and how this is situated within a larger local, regional, or global community. For example, a study of how the New York Port Authority addressed the issue of homelessness at its facilities demonstrated the importance of organizational identity in the interpretation of issues (Dutton \& Dukerich 1991). The use of Port Authority facilities by homeless people threatened the organization's identity as a professional organization. Members saw the Port Authority as an 
organization holding technical expertise but ill-suited to solving social service problems (Dutton \& Dukerich 1991). This shared identity of technical proficiency and social service incapacity shaped the organization's early approaches to the issue and the external salience of the issue made identity the primary lens through which members interpreted it.

More generally, work on corporate social responsibility suggests that organizational identities are more salient to employees of some companies than they are for others (Bhattacharya \& Sen 2003). For example, a consumer products company may have salient elements of its identity bound up in an image of green marketing and it may work hard to maintain this image. In contrast, a company that supplies raw materials to a third tier auto supplier will still have an identity, but its environmental aspects may be much less salient and important to its members.

Organizational Self-monitoring. A further internal factor, one that is related to but still distinct from those we have just discussed, shows up as a company's propensity to engage with outsiders. We label this organizational "self-monitoring," following the important psychological construct of individual self-monitoring (Snyder 1974). Organizational self-monitoring represents a set of choices about how an organization portrays its image to outsiders, in response to its impressions of those outsiders and the value it places on adhering to socially appropriate portrayals. It can show up as the degree of openness, trust, and reciprocity that an organization's members have towards key external groups, including regulatory agencies, communities, activist organizations, and others.

Individual self-monitoring refers to the extent to which individuals strategically cultivate their public behaviors and expressions (Gangestad \& Snyder 2000). High self-monitors are highly attuned to appropriate social display and readily adapt their behavior to be situationally 
appropriate; low self-monitors are not as concerned about the appropriateness of their social displays and hence their expressive behavior consistently represents their inner attitudes and dispositions. Importantly, both low and high self-monitors are equally capable of making judgments about appropriate social behavior and may have similar core identities; they just care differently about acting within social norms and express their identities differently. By analogy, organizational self-monitoring captures the fact that some organizations place more value on acting in ways that are socially appropriate, and consequently seek recognition and reward for their externally directed behaviors. Other organizations, populated by those who are equally aware of socially appropriate behaviors and equally committed to "doing the right thing," nonetheless shun recognition or reward and actively avoid projecting such a public image.

Of all the organizational factors we present here, organizational self-monitoring is the least developed in the literature. Yet we need look no further than companies' public positions on climate change to garner useful examples. In many sectors, some companies have made highly publicized statements of their positions and commitments on climate change, while their industry counterparts - selling to the same markets - have remained silent on the issue. In neither case should the public statements be taken as fully indicative of the actual actions each company is undertaking to mitigate climate change impacts. They reveal, though, that different companies can place a different emphasis on their organization's appearance to the outside world. More generally, we might expect high organizational self-monitors to undertake a large number of beyond-compliance or voluntary actions, particularly those that actively engage external audiences. Low organizational self-monitors might be equally attentive to environmental performance, but less likely to participate in programs that offer external recognition. 
Personal Commitments and Affiliations. Finally, we expect that individuals' own affiliations and commitments matter to how they set and solve environmental problems. For example, professional education, experience, and affiliations shape how people classify and categorize problems (Van Maanen \& Barley 1984). Broadly speaking, engineers, managers, and operators have different concerns and approaches that can transcend the incentives or culture of any given company (Schein 1996). Members of particular professions interact through conventions, training, journals, and professional communications and these activities may influence the approaches they champion within their companies. For example, professional associations and their members likely play a key role in spreading and rationalizing certain environmental management practices, like the use of environmental management systems or other tools and techniques.

Purely personal, individual factors can also influence how a manager perceives the benefits and costs of beyond-compliance environmental activities. A significant fraction of the workforce now identifies with environmentalism and it is increasingly accepted that employees will bring their personal commitments and values to work (Morrison 1991). One empirical study found that employees’ values, and their fit with their company's values, influenced the scope and strength of responses to employee-generated environmental initiatives (Bansal 2003). Others have suggested that managers' individual attitudes toward the environment can shape their organizations’ commitment to addressing environmental issues (Coglianese \& Nash 2001).

Interaction of Factors. Having elaborated five internal factors likely to affect business behavior, we do not mean to suggest that they all matter equally, in all circumstances. On the contrary, we would expect that in some instances one or more of these factors will dominate over others, and that in some instances certain factors may well lie dormant. We would also expect 
that the five organizational and individual-level factors that contribute to an internally constructed license to operate will interact with each other. For example, the most fervent advocate of environmental practices might be unable to convince her company to adopt a beyond-compliance program if formal and informal organizational incentives severely limit managerial discretion. Conversely, an individual with limited personal interest in environmental issues may nevertheless be guided by his company’s strong identity as an innovator and leader on environmental performance.

\section{A Study of Participation in a Major Voluntary Environmental Program}

Ultimately, it is an empirical matter how these internal factors interact with each other and with external factors, as well as the relative importance they play in affecting the overall license to operate. In this section of our article, we take advantage of interview data from a set of matched industrial facilities in an effort to begin to assess the preceding theoretical account of the types of internal factors that may influence businesses' beyond-compliance behavior. Relying on our interviews, we examine an equal number of matched participants and non-participants in the EPA's National Environmental Performance Track to see if we can observe any systematic differences between the two groups. While these interviews could not provide all of the detailed evidence suggested in Table 1, the data we did collect from our interviews suggest that at least three of the five internal factors have contributed to the differences in the environmental management choices made by the facilities we studied.

The NEPT program seeks to recognize, reward, and encourage facilities that are "top environmental performers” (EPA 2005a: 2). The mission of the program is to improve environmental performance, transform relationships between facilities and agencies, and encourage innovation (EPA 2004a). To be admitted, a facility must have a proven record of 
regulatory compliance, an operational environmental management system, a history of environmental achievements that go beyond legal requirements, and a commitment to performance reporting and outreach to the local community and the public. Facilities apply to NEPT by completing standard application materials and submitting them during one of two application cycles scheduled each year. Facilities must describe their environmental management system, submit an "environmental requirements checklist" detailing the environmental regulations they are currently subject to, and provide the names and contact information of three community references. Importantly, they must also make commitments to improve their environmental performance in ways that go beyond what they are required to do by law. ${ }^{2}$ If admitted, facilities are required to submit annual reports to EPA on their progress. Their membership lasts for three years' duration, after which facilities must reapply.

Facilities that are admitted to NEPT are offered recognition, networking opportunities, and certain kinds of limited regulatory and administrative incentives. For example, EPA allows members to use the NEPT logo at facility sites and in promotional materials, and the agency variously sends letters to relevant elected officials announcing a facility's acceptance to the program, submits articles to trade journals about members, and highlights members' names on the agency's website. EPA has also deemed NEPT facilities to be a low priority for routine federal inspections (EPA 2006). ${ }^{3}$ In addition, NEPT plants are allowed to file certain required air pollution reports less frequently and may store hazardous wastes on-site for a somewhat longer period of time without obtaining a RCRA permit (EPA 2004b).

Out of the hundreds of thousands of industrial facilities in the United States, only about 440 have enrolled in NEPT as of September, 2007 (EPA 2007). With many eligible plants not 
participating, ${ }^{4}$ NEPT presents a valuable opportunity to understand differences between participants and non-participants.

\section{Study Design}

We matched five facilities that chose to participate in NEPT (“NEPT facilities”) with five closely comparable non-participating facilities (“matched facilities”). Within each matched pair, the facilities shared similar industrial processes, were of roughly equivalent size and output, had similar environmental compliance records, and operated in demographically similar locations in the region. ${ }^{5}$ This matched data set allowed us to control for key factors that are known to shape facilities' regulatory, social, and economic licenses to operate, enabling us to probe for internal factors that influenced the environmental management decisions made at each facility, including the specific decision about whether to join NEPT. This design overcomes an important limitation common to many studies of voluntary program participation. For example, the EPA's own assessments of NEPT have focused only on participants (e.g., EPA 2003; EPA 2004a; EPA 2005b; EPA 2006). Several scholarly articles have compared participants and non-participants in other voluntary programs (see, e.g., Arora \& Cason 1995; Arora \& Cason 1996; DeCanio \& Watkins 1998; Khanna \& Damon 1999), but the principal focus in the literature has remained on externally observable differences that are associated with participation. By focusing on internal factors, and choosing matched companies based on their decisions to participate in a single voluntary program, our study design opens up the possibility of discerning internal differences between otherwise similar participants and non-participants.

We identified NEPT members for this study using the list of participating facilities by region on the EPA's website. We focused on a single region with a large number of NEPT facilities (39 at the time of the study). Since eighteen of these NEPT facilities (46\%) had been in the program since its inception, we selected our sample from among these "charter" NEPT members. We 
limited our sample still further by eliminating those facilities that were not subject to the EPA's Toxics Release Inventory (TRI) reporting requirements. We also eliminated facilities owned by Johnson \& Johnson, Inc., a company with 40 facilities enrolled in NEPT at its inception, far more than any firm. ${ }^{6}$ Of the remaining facilities, we selected for study all those for which we could find suitable matches.

The following data were collected to match NEPT facilities with nonparticipating facilities: the four-digit SIC or NAICS codes, number of employees, sales, demographic profile of the surrounding community, and history of environmental regulatory compliance. We gathered information about facility size (number of employees and sales) from OneSource Information Services, Inc. We obtained data on community demographics, regulatory compliance, and environmental permitting from the EPA's Enforcement and Compliance History Online (ECHO) and the U.S. Census. Using EPA's Envirofacts database, we collected information about each facility’s total aggregate TRI releases during the period beginning 1987 through to 2003, the latest year for which information was available. We used the compliance, permitting, and TRI data to compare the facilities' environmental performance. Table 2 summarizes characteristics of NEPT and matched facilities, using a pseudonym for each facility.

Table 2 about here

There was little difference between NEPT and matched facilities on dimensions of environmental performance. First, we found that both NEPT participants and non-participants had similar environmental performance records. Each of the facilities in our study had a "clean" compliance history; at the time of our interviews, none had been subject to any enforcement 
actions by state or federal environmental agencies for the prior two years, according to EPA's Enforcement and Compliance History Online (ECHO) database. ${ }^{7}$ Further, the TRI data for the period 1987 to 2003 suggested similar overall trends in the reduction of TRI releases for all facilities. ${ }^{8}$ With one exception, all facilities had achieved reductions. ${ }^{9}$ We noted that three of the five NEPT facilities had reduced releases substantially in the early 1990s, while the matched facilities had lower releases to start out and had achieved further, comparable reductions more incrementally.

All of the facilities we studied were subject to similar environmental regulatory permit requirements. All ten facilities had hazardous waste permits: four of the five NEPT plants were Large Quantity Generators of hazardous waste, while all five matching plants had this designation. Three NEPT facilities had active air discharge permits, while all five of the matching plants were subject to air permitting requirements. Two NEPT plants held water discharge permits, as did two matching plants. All plants had been inspected at some time by EPA or state environmental agencies. We attempted to match facilities whenever possible based on whether they had received a recent inspection, specifically within a two year period prior to our interviews. ${ }^{10}$

Finally, all facilities operated some form of environmental management system (EMS). All of the NEPT facilities were certified to ISO 14001, an international standard for EMSs, while only one matched facility had an ISO 14001 certified EMS. However, two of the other four matched facilities had independently certified EMSs and the remaining two operated noncertified EMSs. Table 3 summarizes aspects of the facilities' environmental performance, practice, and regulatory requirements. 
Table 3 about here

\section{Data Collection}

In 2003 and 2004, we conducted in-person, not-for-attribution, semi-structured interviews with plant-level environmental managers at each facility. We focused our interviews at the facility level because from its inception NEPT has been a program aimed at participation by facilities, not overall companies. Once we had identified an appropriate non-participating match for each NEPT facility, every effort was made to conduct interviews at those plants. Where managers of nonparticipating facilities were not responsive, we repeated our requests and assured them that the discussion would not be attributed to them or their facilities. With persistence, we were able to conduct an interview with a plant-level environmental manager at every matching facility we had identified. By doing so, we reduced the bias that comes from limiting the selection of study facilities to those that readily take part in research about voluntary environmental programs. Interviews ranged in length from one to two hours and were tape recorded and professionally transcribed.

Because we were interested in understanding the internal context for and influences on environmental decision making at the facility level, our interviews probed broadly for significant events, developments, and challenges each respondent perceived or experienced. Each respondent was asked about: 1) changes the facility had made in its environmental management in the preceding few years, reasons for these changes, and staff involved; 2) actions the facility had taken to improve awareness of environmental management activities and actions or 
arguments that were or could be made to influence key decision makers; and 3) respondents' experiences with voluntary programs in general and their perceptions of the costs and benefits of such programs to their facilities. Importantly, NEPT was not mentioned until late in the interview during the discussion of voluntary programs, unless the respondent volunteered information about the program earlier. This interview protocol allowed us to elicit respondents’ broad attributions and assessments of events or factors (external and internal) that shaped environmental management decision making and actions at the facility. In addition, by focusing on how the respondents sought to influence others, we were able to gather information on internal barriers or opportunities that might have been posed by structure, culture, or incentives. The interview guide was not shown to respondents in advance to ensure that they did not approach the interview as being "about" NEPT. Interviews proceeded in an open-ended fashion which resulted in the collection of rich qualitative data on how individual managers perceived their facilities' environmental activities and performance, well beyond their participation or nonparticipation in NEPT. Consistent with our exploratory qualitative research approach, we did not probe for specific information on organizational culture, identity, or self-monitoring in order to avoid presupposing key influences on environmental management. Instead, we used our interviews to gather manager's own insights and gain detail that we used to develop further our theoretically derived factors. ${ }^{11}$

\section{Data Analysis}

We began our data analysis by having each author read all interview transcripts individually, looking for emergent themes (Glaser \& Strauss 1967). From these, we compiled a list of initial codes that we used to code the interviews qualitatively (Miles \& Huberman 1994). Initial codes covered both external factors (e.g., customer demands, community pressures) and internal factors (e.g., managerial support, organizational structure, identity) mentioned by respondents as 
important to their facilities' environmental practices. We also included codes for respondents' judgments of the value and effectiveness of NEPT and other beyond-compliance behaviors. A research assistant who was not aware of which facilities were members of NEPT coded the interviews in random order, starting with the list of initial codes and modifying them as new or different themes emerged from the data. The coding was done using Atlas.ti, a qualitative research software package. The research assistant discussed his coding with the authors and we iteratively arrived at a final list of codes and assured that the coding was applied consistently and comprehensively.

Once the coding was completed, we performed both "within-case" and "between-case" analyses (Miles \& Huberman 1994). For each facility, we summarized the results of the coding on a figure to represent the internal and external factors that, according to the managers interviewed, informed their environmental management practices and their decisions about joining NEPT or taking other beyond-compliance activities. We also attended to how the content of each set of codes differed between NEPT and the matched facilities, as groups. These comparisons are reported below.

\section{Factors Explaining Performance Track Participation}

The interview data showed no systematic differences between NEPT and matched facilities in how their managers viewed regulatory requirements, nor how they viewed other external social or economic pressures. In all cases, facility environmental managers regarded compliance with regulation as a given. As one NEPT participant noted, "it's basically the rule of the land, you have to do this or do that.” A matched facility manager similarly observed, “you just can't afford not to pay attention to this stuff." 
In addition, both NEPT and matched facility managers commented on what they perceived as inconsistent or irrational details of regulation. One NEPT manager gave the following example:

We have to file the paperwork within 35 days. That's by federal law. One of the states said you have to file it in 30 days. So I don't know what those five days difference is going to do, aside from you're creating one more paragraph, you're creating one more law,...that is what I consider nonsense with the regulation.

A matched facility manager similarly commented that "I never get a real strong sense that the regulatory community fully puts a lot of these things in perspective. And I have real trouble with EPA on that.” Perhaps the only significant difference we encountered between NEPT and matched facility managers centered on how they talked about regulatory pressures. Notwithstanding some NEPT managers' concerns about nonsensical regulation, more NEPT managers portrayed their relationship with regulatory authorities as trusting and flexible, while many of the matched facility managers expressed an overt lack of faith in the regulatory system. We consider these differences further when we consider organizational self-monitoring as one of the internal factors affecting the license to operate.

Economic pressures for environmental practices were mentioned only infrequently in the interviews, with no systematic difference in the portrayals given by respondents from NEPT and matched facilities. By and large, the managers we spoke with represented the economic influences on their decisions in terms of supplier or customer demands. One manager was representative of others when, asked if his business customers cared about the facility's environmental management practices, he responded, “some do, some don't.” One NEPT manager observed that "[t]here is very little articulated demand for excellence from our customers." 
Similarly, social pressures were noted by both NEPT and matched facility managers but it was not clear that one set or the other faced systematically different pressures that shaped their environmental actions. Virtually all of the managers noted that maintaining a good relationship with the community was important, whether they felt their operations were hazardous or not. One matched facility manager observed, "if something [environmental] comes up, we present ourselves before the Town Council and they know us, they know us from the past ... we have a good relationship with our community." What did differ between the two groups of facilities was the value managers placed on this relationship with the community and other outsiders, relative to other priorities. We will address this point in more detail below in our discussion of the internal construction of the license to operate.

Overall, we could not discern any significant difference between the NEPT and matched facilities based on the external influences typically regarded as comprising the license to operate. Neither economic nor social explanations were highly elaborated in the interviews, and differences were not apparent between NEPT and matched facilities on either dimension that would predict differences in environmental management activities. Further, the differences in perception and trust of regulators, rather than the regulatory environment faced, seemed to be the only significant difference between these two groups. Combined with the results reported earlier that showed almost identical environmental performance trends and compliance records, the interview data on external pressures suggests that we need to look further to explain the divergent behavior of the NEPT and matched facilities.

\section{Internal Factors and the License to Operate}

Earlier we identified five factors internal to companies that, based on theory and prior empirical evidence, we would expect to contribute to the construction of the license to operate. From our data set, we find notable evidence confirming the importance of at least three of these 
five factors. We observed strong and consistent differences in the coded interview data in terms of managerial incentives, organizational identity, and organizational self-monitoring. That we did not find confirmation of the other factors does not necessarily mean they do not matter. Our method, constrained by our limited access to non-participating facilities, did not enable us to make a close analysis of organizational culture. The interviews also were not conducted specifically to discern personal commitments or professional affiliations that might shape perceptions and actions on environmental issues. The interviews did offer occasional hints at the importance of culture and personal commitments, ${ }^{12}$ but we found a much stronger indication of the importance of managerial incentives, organizational identity, and organizational selfmonitoring. In this section, we report representative interview evidence illustrating each of these three factors and how they varied between participating and non-participating facilities.

Managerial Incentives. While the formal structure within each company was largely similar (for example, 9 facilities were part of a larger corporate structure), ${ }^{13}$ managers from the NEPT and matched facilities spoke differently about the degree of autonomy they enjoyed within such structures, the degree of support from their superiors in pursuing voluntary programs, and their tacit rewards and incentives for doing so. In other words, the informal aspects of the organizational structure seemed to create a different set of incentives for the NEPT versus matched facilities.

NEPT facility managers spoke of very clear management support from both their direct management and from higher levels. One noted that "my boss, the director of operations for the site, backed me up when I found out about the [Performance Track] program and suggested we join.” Others spoke of the involvement and knowledge of corporate managers in their environmental programs, with one noting that a manager from the corporate office said, "Hey, 
you might want to consider this [joining NEPT].” Similarly, NEPT managers spoke of the incentives they received to manage environmental programs in a certain way and the fit of Performance Track with these incentives. One noted that:

It seemed to me that our readiness to participate in Performance Track was pretty good because they [management] were looking for very measurable and quantifiable things that you could say, OK, here's where we are and here's what we might set as some targets for future improvement.

Another manager described how she had turned down business from her parent company because it would have required formulating chemicals that had been eliminated from the plant for health reasons. "My boss backed me up," she added, "He understands that we need to keep a positive direction.”

Although the majority of the NEPT facilities were part of a larger corporate structure, these managers tended to speak about the autonomy they had to implement programs that were consistent with corporate objectives. One observed that, in joining Performance Track, "we didn't need signoff from our parent company, but they would have been supportive if we'd asked because it’s consistent with their philosophy of excellence.” Another noted that he pursued participation in Performance Track because it was a program that would help "gain that bottomline improvement that our management has come to expect of us.”

The majority of the matched facilities were also part of larger corporations, but in at least several of these the organization's structure and decision processes seemed to act more as a constraint than an enabler for individual facilities and managers. One matched facility manager noted that "the [parent] company provides for the environmental management system." He added that participation in a voluntary program was "probably something of interest [to his site] but ... we generally do things together," noting that he had very limited autonomy to work outside the 
programs prescribed by the corporate EH\&S group. Another manager suggested that making a decision to participate in a voluntary program was not within his purview. He observed:

I think of our site level as an operation site. You know, we have not talked about doing some of those programs. It's really the worldwide environmental health and safety level.

The matched facility managers also spoke of much less direct managerial support for voluntary programs. One said, “sure they [management] would care, but it’s a matter of degree. How much would they care?” Another manager suggested a relationship with corporate management that was very hands-off: "What I'm looking for is a handshake from our corporate environmental auditor.”

These differences in incentives were associated with differences in perceptions of the benefits and costs of Performance Track. The NEPT participants generally regarded the program as relatively low cost to join and saw synergies between joining and using their existing environmental management process, such as ISO 14001 certification. One NEPT facility manager noted that, "because we already had our ISO 14001 certification at the time we joined PT, the costs have been pretty minimal. Just a few hours of my time.” Similarly, a second observed, "It was a fairly easy decision to join since we had most of the elements already in place. We had an EMS that had been certified in 1998." One noted that "this initiative aligned perfectly [with our business] as have some others that we're involved in within the community for example.”

In contrast, managers from the matched facilities spoke of the significant costs of participation in voluntary programs in terms of time and resources. One commented that "you have all this stuff to worry about, and one of the things that's important is to begin to prioritize things. You just can’t do everything.” Another added, 
When we look at efforts we have a lot of justifications and investments, and we don't do an awful lot of them just because they're fun. I don't have time to do something just because it might be interesting or personally gratifying.

Incentives for these managers seem to be focused quite heavily on audits, and in particular, in satisfying internal or third party auditors. One manager remarked,

When I have an audit, what's in my mind is that I can answer all their questions and that they won't come back with significant lists of things to follow up on.

Relative to other priorities, these managers saw the requirements of NEPT and other voluntary programs as distracting from their main focus. As one manager observed, "these are important programs, but so is getting product out the door safely.”

Organizational Identity. Organizational identity came up when managers reflected on their external relations and the focus of their business. We saw some significant differences in how managers spoke about the identities of their companies and facilities. NEPT managers spoke eloquently of their facilities' commitment to strong environmental performance and noted that they raise environmental issues in communications with outsiders. In contrast, matching facility managers spoke of environmental performance in much more practical terms.

The NEPT facility managers' comments often suggested an active stance on environmental issues. For example, one manager noted "our focus is on quality, health, and safety. That's the core business at this site.” Furthermore, in this case, the manager cited the parent company as a strong proponent of environmental management which supported the facility's efforts. Acquired by the parent three years earlier, the facility's identity extended further back in time; "even before that we had a mindset of excellence,” the manager noted.

NEPT managers also commented on how their image, particularly with the community, played into their efforts to cultivate or maintain a strong environmental identity. One commented that "we are now looking for outreach into the community and otherwise to continue our promotion in advancement of environmental awareness and that sort of thing.” Another admitted 
that "we had been working on our public image because we did have a tainted past. We just thought that this would be another good way to promote ourselves as being environmentally aware and conscious.”

An additional “measure” of managers' openness is their response to requests to be interviewed. In all NEPT cases, it took only one telephone call following an initial contact letter to set up an interview. For three of the matched facilities, it took four or more calls.

In contrast to NEPT facilities, managers from the matched facilities had more pragmatic expressions about their company's identities which typically focused on "doing the right thing” including operating safely, staying within the law, and doing what made sense for the business. They saw environmental management as an important part of their identity - one manager said "if we had a choice to be known as environmental do-gooders versus environmental sinners, we'd take do-gooders every day.” But then, this same company largely shunned participation in voluntary programs as a way to develop this identity. Another manager noted that, "I think from a practical standpoint, we always try to do the right thing and we're not as driven by regulation as by common sense and gut feeling." Another asserted that “it’s our site, and we're spending our money doing it. If it’s not done right, we're going to have to re-do it. So of course we're going to do it right.” Finally, one observed

If you look to the bottom line, if you want to keep manufacturing more in order to minimize your footprint, you have to use less chemical[s], less water, try to generate less waste or try to recycle more.

Consistent with this identity, these managers shunned the "paperwork" associated with voluntary environmental practices, including environmental management systems, and instead spoke of how they prioritized their actions to focus on tangible results. One summed up his facility’s decision not to participate in a government-run environmental voluntary program in this way: 
It's more paperwork. And our company wants to do what's right; it has that moral intent to it. So if my job is the do the right thing I'd prefer doing it without making a big paper trail and making sure my i's are dotted and my t's are crossed.

Organizational Self-monitoring. We saw considerable differences between the NEPT and matched facilities on the dimension of organizational self-monitoring, with managers from the NEPT facilities talking about how much they valued ties with regulators and positive relations with other external actors. Matched facility managers seemed less interested in recognition and spoke more of taking care of their business and its environmental impacts, rather than advertising their behavior to outsiders.

Recognition from the immediate community was very important according to many of the NEPT facility managers. One noted that "if we can get in the newspaper having received some [state agency] or EPA award or some recognition ... it plays well.” Another, commenting on the facility's certified EMS and participation in voluntary programs, observed that "all of these programs are advertising. Some of the programs carry more weight, but every little thing can help in public relations and marketing.” Beyond the community, firms in this group wanted to be seen as environmentally aware with their employees. One commented that "if EPA stamps their approval on your facility program ... that does wonders for the morale for people here as well as in the local community."

Contrast these comments with those made by matched facility managers who generally asserted that performance, not recognition, was most important in their relationships with others. One noted that "as long as we get it done, that's what matters, not necessarily that we get recognized for it.” He added, “we should be reducing our risk. That’s what people care about. They don’t care about fluffy management practices.” Another manager echoed this sentiment, 
saying, "at the end of the day it's how many losses did you have, and did you have fewer injuries, fewer spills, fewer incidents.”

There was a similar contrast between how NEPT and matched facility managers spoke of their interactions with regulators. Several of the NEPT managers were very open and forward in their interactions with regulators; they clearly valued building and maintaining a positive relationship with state and federal environmental agencies. For example, one NEPT manager noted that his facility had "built up positive karma ... where now when we relate with a regulator we can relate in a position of trust.” This manager now felt comfortable going to the EPA and state regulators and "saying to them look, there are other ways of doing it [meeting regulatory requirements].” Another manager noted that “the recognition that EPA give us validates what we're trying to do.”

While some matched facility managers also recognized the need for good will between their facilities and regulators (e.g., "I think there’s definitely a correlation between... [the company] being proactive in some spaces and developing a relationship with [state regulators] that's helpful”), others were very clear that they regarded regulators as untrustworthy and were unwilling to see them as partners. One manager, commenting on the EPA, suggested “they don't trust anybody ... and I don’t trust the agency.” Another observed that,

They're [the EPA] just too big, too dysfunctional, too many lawyers. Not enough risk people. And too focused in on command and control, too much paper, too much garbage, and not enough result.

Rather than seeing themselves as capable of working in partnership with regulators, these managers actively dismissed this approach. One manager asserted

EPA wants a partnership. I'm looking for a cop. Shut me down if I violate my permit. Otherwise leave me alone. 
Like low individual self-monitors, managers in this group recognized what comprised socially desirable behaviors, and at times attempted to conform, but largely implied that conformance was not very important to them or their companies. One drew this analogy:

[T]en years ago, our environmental commitment was like brushing our teeth. We did it every day, but we didn't talk about it. Now we have a documented procedure for brushing our teeth and write a note every time we brush. We document everything because that's part of being open.

The behavior required to appeal to agencies, in this case the establishment of a formal EMS, held little intrinsic meaning to this manager. Another, commenting on standard practices expected of industry suggested,

EPA comes in with a checklist. If I spent all my time taking care of what's on their checklist, my plant would probably blow up.

For these managers, like low individual self-monitors, performance itself, rather than adherence to outsiders' criteria for performance, was most important. As one asserted, “It's always nice to be recognized for advancement, but ultimately it's the advancement that matters.”

\section{Discussion}

In this article, we have explored the internal factors that affect facilities' licenses to operate, complementing but extending earlier work on the external (regulatory, social, and economic) aspects of licenses to operate. In order to bring together disparate work on internal factors that shape corporate environmental practices, we posited that the license to operate is affected by at least five core organizational and individual factors: managerial incentives, organizational culture, organizational identity, organizational self-monitoring, and personal or professional affiliations and commitments.

Although the license to operate is clearly shaped by the external conditions the company faces and its historic engagement with outsiders around particular issues, there are strong reasons to believe the license also is independently influenced by internal factors. Because it is informed 
by key organizational factors that are much larger than environmental management alone, the license to operate may be resistant to changes in external environmental pressures, or, conversely, responsive to changes in internal pressures that may be completely unrelated to environmental issues (e.g., a leadership change). For this reason, connecting particular external conditions or incentives to internal management or culture change (or vice versa) must be done very carefully. The causality of such connections is complex, and internal factors can create inertia or significant managerial agency (or both), each of which significantly influences a company's responsiveness to external conditions.

While our matched facility data support the argument that key internal factors - most notably in this study, managerial incentives, organizational identity, and organizational selfmonitoring - influence managers' environmental management decision making, our analysis is certainly not exhaustive nor fully determinative. Our effort is a starting point for others to explore further the specific internal factors we have identified, as well as other factors that may contribute to the internal construction of a company's license to operate. Several opportunities for future research are present.

First, to test whether the three factors we found most prevalent in our interview data indeed influence environmental management decisions, one could design further studies of matched facilities. Selecting, as we did, a sample that includes both participants and non-participants in a single voluntary program, a survey could be designed to develop understanding of these three factors. Managerial incentives may be operationalized through questions about direct incentives (e.g., compensation tied to environmental performance), formal structure (e.g., vertical and lateral channels of communication and control), and informal influences (e.g., degree of direct management support for new initiatives in general, or environmental initiatives specifically). 
Organizational identity could be operationalized through open-ended questions asking managers to describe in a short sentence what is central and distinctive about their company and its business approach, and questions that offered paired selections of identity descriptors (e.g. innovative vs. conservative) and asking managers to select one from each pair that best describes their organization. Finally, organizational self-monitoring might be measured through questions that assess the number and type of external engagements or partnerships the company or facility has initiated, or the propensity of managers in general to seek external outreach versus taking a more reactive stance. With a sample of sufficient size, factor analysis could be used to assess whether the various proposed measures of the three factors are meaningful, and regression analysis could be used to assess whether these factors (or others) influence the dependent variable, voluntary program participation, while controlling for other variables such as industry, size and demographic composition of the community.

A second extension to this work could seek to extend, develop, and further understand the five factors proposed here by developing measures that would identify and discern each factor, as well as test which factors are more important than others. To develop measures, further qualitative research using in-depth interviews would be very helpful to gain insight into, for example, the impact of organizational culture on environmental decision making. This type of research could be used to inform future survey research that could operationalize and test all five factors (and any others that are suggested by the qualitative studies). In addition, comparative research across industries, types of facilities, or types of voluntary programs could be used to understand the combinations of internal factors that might be particularly important (or unimportant) in shaping managerial decision making on environmental issues. Of course, any such study would have to control for external conditions or other influences. Single companies 
that operate a large number of facilities may be useful cases to study as they hold constant at least some of the variables (e.g. corporate structure) allowing for potential variance to be observed in others (e.g., manager's personal affiliations or commitments). Of course, in any such study the outcome variable (e.g. participation in a voluntary program) would have to represent, as with NEPT, a decision by the facility rather than the corporation overall.

Finally, better understanding of the interaction between internal and external factors on environmental decision making could be gained from longitudinal case studies. While the questions of controls and comparability are ever-present in such approaches, case studies of handfuls of facilities over a long period of time could be very valuable in developing a clearer understanding of the processes by which internal factors and external conditions interact. Methods such as in-depth interviewing and direct observation would be valuable to develop a close understanding of internal factors, as well as insight into how managers interpret external conditions and set and solve environmental problems.

\section{Conclusion}

Those who have pointed to internal, managerial factors as shaping corporate environmental practices have had good reason to do so, for external factors cannot tell the full story. In this article, we have attempted to provide both theoretical and empirical grounding for the internal factors that shape decisions to adopt certain beyond-compliance behaviors. Our analysis has several implications for the literature on corporate environmental practice and beyond-compliance behavior, and for practice and policy in these areas. First, by articulating five internal factors that we expect contribute to how particular companies select problems for attention and act on them, we extend and elaborate in greater theoretical detail the constructs of environmental management style (Gunningham et al. 2003) and managerial commitment (Coglianese \& Nash 2001) that have been deployed in the literature to date. Better understanding 
of the complex interactions between internal organizational factors and external pressures in shaping environmental decision making, and ultimately environmental performance, can be gained by further studies that develop and test the internal factors we have analyzed here.

Second, our empirical data suggest that there is likely a set of businesses that seek and obtain recognition through a constellation of beyond-compliance initiatives, and another set that does not. Just as individuals differ in their self-monitoring behavior - namely, in how closely they match their public behaviors to socially desirable displays and in their desire for recognition - our data suggest that businesses have analogous propensities. This finding could have immediate implications for how voluntary environmental programs are evaluated. For example, surveying managers to see how satisfied they are with the voluntary programs they join may be rather meaningless, since almost by definition those who join are happy to join (Coglianese 2003).

Finally, our findings serve as a caution for outsiders not automatically to identify those who seek and receive recognition as leaders and those who do not as laggards, for they may perform equally well in terms of compliance and pollution reduction. Companies shape others' images of them, and such images can influence the pressures external organizations place on them (Gunningham et al. 2003; Howard-Grenville 2005). Given this fact, we can probably expect companies that value and seek external recognition to engage in activities that positively reshape external aspects of their licenses to operate, while those who place less value on external recognition not to do so. While the ability of companies to influence external pressures could be taken as an argument for companies to engage proactively in beyond-compliance behavior, it should also be taken as a warning to observers of such behavior not to overestimate the differences in performance among firms that cultivate external recognition and those that do not. 


\section{Notes}

${ }^{1}$ Following Gunningham et al. (2003) and others, our focus is explicitly on beyond-compliance behavior, although we suspect that much of our theoretical account and empirical findings could also bear on business decisions about complying with regulations. The differences, if any, in explanatory models for compliance and beyond-compliance behavior merit further inquiry but extend beyond the scope of this article.

${ }^{2}$ Facilities with fewer than 50 employees must make only two such commitments; larger facilities must make four.

${ }^{3}$ Some state environmental departments also avoid inspecting NEPT plants on a routine basis.

${ }^{4}$ Determining the number of facilities that would be eligible for the program is difficult. Some 5,000 facilities in the United States have become certified to ISO 14001, the international environmental management system (EMS) standard, and would meet the program's EMS requirement (ISO 2006). Many more facilities have implemented EMSs that would probably still qualify them for Performance Track.

${ }^{5}$ To be sure, outside of a laboratory setting, no such empirical matching effort will be perfect along every dimension. Like others who have used a similar research design in other areas (e.g., Shapiro 2002), we claim only to have made the best possible effort to match facilities on observable characteristics. The facilities in our study were matched in the first instance by operating in precisely the same line of business and in the same EPA region. Other characteristics, such as the number of employees or community demographics, cannot be exactly the same but are sufficiently comparable that we do not expect any of the modest differences to explain differences in behavior. In selecting these five matched pairs, we rejected other possible matches where differences in observable characteristics were more pronounced.

${ }^{6}$ Starting with the launch of NEPT, Johnson \& Johnson had announced a corporate-wide commitment to have all of its facilities join EPA's program. We therefore excluded its facilities from our study for two reasons. First, since no other major corporation had made a similar company-wide commitment at that point, we concluded that Johnson \& Johnson facilities would not represent the "typical" case of a facility deciding whether to join NEPT. Second, the very fact that Johnson \& Johnson facilities joined because of a corporate directive provides support all on its own for the importance of internal factors in explaining business behavior. Facility managers within Johnson \& Johnson clearly found themselves facing different managerial incentives - not to mention other organizational factors - than did managers at facilities elsewhere. Excluding Johnson \& Johnson from our sample therefore followed appropriate qualitative research methods by ensuring that we did not select cases that would be more likely to support our theoretical prediction that internal factors affect beyond-compliance behavior (King, Keohane \& Verba 1994). ${ }^{7}$ Using ECHO, we also checked for any other indication of a regulatory violation at our respondent facilities. For the three years prior to our interviews, we found no violations for any of the facilities included in our study. Subsequent to our interviews, we did discover that one of the matched facilities had one "non-significant" violation for one quarter within the three-year period. It is not uncommon, of course, for regulated facilities to have a minor violation from time to time. In fact, one can search ECHO and find that in 2007 about twenty-percent of all the Performance Track facilities in the database had a violation noted, about a dozen of which actually were listed as being "significant."

${ }^{8}$ Because our goal was to assess overall trends in TRI releases, we did not attempt to normalize releases but compared each matched pair's trends in aggregate releases over time.

${ }^{9}$ At one matching facility, toxic releases had increased following a change in the products manufactured at the site.

${ }^{10}$ Interestingly, three of the five NEPT plants had been inspected in recent years even though the EPA offers lowinspection priority as a benefit to NEPT members.

${ }^{11}$ At each facility, we interviewed the key environmental manager who would have been most closely involved in the facility's decision about participating in NEPT. With the exception of one NEPT facility where our interview consisted of a meeting with the facility manager and plant manager together, our study is limited to only one respondent per facility. While more interviews at each facility would always be better, the practical constraints of obtaining any access at all to non-NEPT facilities were such that obtaining more than a single interview was often not feasible. For symmetry, we similarly limited our interviews for NEPT facilities wherever possible. Given the early stage of overall research on internal factors affecting beyond-compliance behavior, and the necessarily exploratory nature of our empirical work, the number of interview respondents is clearly not inappropriate. Our number of respondents per facility is comparable to that found in studies that rely on survey methods, and not out of line with other interview-based studies.

${ }^{12}$ The lack of evidence about cultural influences is to be expected, partly as a result of the study design. It is difficult to gain insight into culture without repeated observation as members often have a hard time articulating their own 
culture (Schein 1992). This limitation in our design could be overcome in a study that gained a more holistic understanding of organizational culture through direct, longitudinal observation supplemented with in-depth interviews.

${ }^{13}$ These corporate structures typically consisted of multiple plants producing products for a single industry and reporting to a corporate parent. They did not include subsidiary relationships or other forms of corporate control. 


\section{References}

Albert, Stuart, Blake Ashforth and Jane Dutton (2000) "Organizational Identity and Identification: Charting New Waters and Building New Bridges,” Academy of Management Review 25: 13-17.

Albert, Stuart, and David Whetten (1985) “Organizational identity,” Research in Organizational Behavior 7: 263-295.

Allison, Graham, and Philip Zelikow (1999) Essence of Decision: Explaining the Cuban Missile Crisis $\left(2^{\text {nd }}\right.$ ed.) Reading, Mass.: Longman.

Andersson, Lynne, and Thomas Bateman (2000) "Individual Environmental Initiative: Championing Natural Environmental Issues in U.S. Business Organizations,” Academy of Management Journal 43: 548-570.

Arora Seema, and Timothy Cason (1995) "An Experiment in Voluntary Environmental Regulation: Participation in EPA's 33/50 Program,” Journal of Environmental Economics and Management 28: 271-286.

Arora, Seema, and Timothy Cason (1996) "Why do Firms Volunteer to Exceed Environmental Regulations? Understanding Participation in EPA's 33/50 Program,” Land Economics 72(4): 413-32.

Ayres, Ian, and John Braithwaite (1992) Responsive Regulation: Transcending the Deregulation Debate. New York: Oxford Univ. Press.

Bansal, Pratima (2003) "From Issues to Actions: The Importance of Individual Concerns and Organizational Values in Responding to Natural Environment Issues,” Organization Science 14: 510-525.

Barnes, Jeb, and Thomas F. Burke (2006) "The Diffusion of Rights: From Law on the Books to Organizational Rights Practices,” Law \& Society Review 40: 493-524

Bhattacharya, C.B., and Sankar Sen (2003) "Consumer-Company Identification: A Framework for Understanding Consumer's Relationships with Companies,” Journal of Marketing 67: 76-88.

Blackman, Allen, and Geoffrey J. Bannister (1998) “Community Pressure and Clean Technology in the Informal Sector: An Econometric Analysis of the Adoption of Propane by Traditional Mexican Brickmakers,” Journal of Environmental Economics and Management 35: 1-21.

Carlile, Paul (2002) "A Pragmatic View of Knowledge and Boundaries: Boundary Objects in New Product Development,” Organization Science 13: 442-455.

Christmann, Petra (2000) "Effects of 'Best Practices' of Environmental Management on Cost Advantage: The Role of Complementary Assets,” Academy of Management Journal 43: $663-680$. 
Coglianese, Cary, and Jennifer Nash (2001) "Environmental Management Systems and the New Policy Agenda.” In Regulating from the Inside: Can Environmental Management Systems Achieve Policy Goals?, edited by C. Coglianese and J. Nash. Washington D.C.: Resources for the Future.

Coglianese, Cary (2003) “Is Satisfaction Success? Evaluating Public Participation in Regulatory Policy Making.” In The Promise and Performance of Environmental Conflict Resolution, edited by R. O’Leary and L. Bingham. Washington, D.C.: Resources for the Future Press.

DeCanio, Stephen J. and Watkins, William E. (1998) "Investment in Energy Efficiency: Do the Characteristics of Firms Matter?,” Review of Economics and Statistics 80: 95-107.

Delmas, Magali, and Arturo Keller (2005) "Free Riding in Voluntary Environmental Programs: The Case of the U.S. EPA WasteWise Program,” Policy Sciences 38: 91-106.

Delmas, Magali, and Anne Terlaak (2001) “A Framework for Analyzing Environmental Voluntary Agreements,” California Management Review 43: 44-63.

Delmas, Magali, and Michael Toffel (2005) “Organizational Receptivity to Institutional Pressure: The Adoption of Environmental Management Practices,” Center for Responsible Business Working Paper, Univ. of California, Berkeley.

Douglas, Mary (1978) Cultural Bias. London: Royal Anthropological Institute of Great Britain and Ireland.

Dutton, Jane, and Susan Ashford (1993) “Selling Issues to Top Management,” Academy of Management Review 18: 397-428.

Dutton, Jane, and Janet Dukerich (1991) "Keeping an Eye on the Mirror: Image and Identity in Organizational Adaptation,” Academy of Management Journal 34: 517-554.

Dutton, Jane, Janet Dukerich, and Celia Harquail (1994) "Organizational Images and Member Identification,” Administrative Science Quarterly 39: 239-263.

Edelman, Lauren, Christopher Uggen, and Howard Erlanger (1999) “The Endogeneity of Legal Regulation: Grievance Procedures as Rational Myth,” American Journal of Sociology 105: 406-454.

Egri, Carolyn, and Susan Herman (2000) “Leadership in the North American Environmental Sector: Values, Leadership Styles, and Contexts of Environmental Leaders and their Organizations,” Academy of Management Journal 43: 571-604.

Esty, Daniel, and Michael Porter (1998) "Industrial Ecology and Competitiveness: Strategic Implications for the Firm,” Journal of Industrial Ecology 2: 35-43.

Forbes, Linda, and John Jermier (2002) “The Institutionalization of Voluntary Organizational Greening and the Ideals of Environmentalism: Lessons about Official Culture from 
Symbolic Organization Theory.” In Organizations, Policy, and the Natural Environment, edited by A. J. Hoffman and M. J. Ventresca. Stanford: Stanford Univ. Press.

Gangestad, Steven, and Mark Snyder (2000) "Self-Monitoring: Appraisal and Reappraisal," Psychological Bulletin 4: 530-555.

Gladwin, Thomas, James Kennelly, and Tara-Shelomith Krauss (1995) "Shifting Paradigms for Sustainable Development: Implications for Management Theory and Research,” Academy of Management Review 20: 874-907.

Glaser, Barney, and Anselm Strauss (1967) The Discovery of Grounded Theory: Strategies for Qualitative Research. New York: Aldine de Gruyter.

Gray, Wayne, and Ronald Shadbegian (2005) "When and Why Do Plants Comply? Paper Mills in the 1980s," Law \& Policy 27: 238-261.

Gregory, Kathleen (1983) "Native-View Paradigms: Multiple Cultures and Culture Conflict in Organizations,” Administrative Science Quarterly 28: 359-376.

Gunningham, Neil, Robert Kagan, and Dorothy Thornton (2003) Shades of Green: Business, Regulation, and Environment. Stanford: Stanford Univ. Press.

Gunningham, Neil, Robert Kagan and Dorothy Thornton (2004) "Social License and Environmental Protection: Why Businesses go Beyond Compliance,” Law \& Social Inquiry 29: 307-341.

Gunningham, Neil, and Robert Kagan (2005) "Regulation and Business Behavior," Law \& Policy 27: 213-218.

Gunningham, Neil, Dorothy Thornton, and Robert Kagan (2005) "Motivating Management: Corporate Compliance in Environmental Protection,” Law \& Policy 27: 289-316.

Haines, Fiona (1997) Corporate Regulation: Beyond 'Punish or Persuade. Oxford: Clarendon Press.

Hatch, Mary Jo and Majken Schultz (2002) "The Dynamics of Organizational Identity," Human Relations 55: 989-1018.

Henriques, Irene, and Perry Sadorsky (1996) "The Determinants of an Environmentally Responsible Firm: An Empirical Approach,” Journal of Environmental Economics and Management 30: 381-95.

Hoffman, Andrew (1999) "Institutional Evolution and Change: Environmentalism and the U.S. Chemical Industry,” Academy of Management Journal 42: 351-371.

Hoffman, Andrew (2000) Competitive Environmental Strategy: A Guide to the Changing Business Landscape. Washington D.C.: Island Press. 
Hoffman, Andrew (2001) From Heresy to Dogma: An Institutional History of Corporate Environmentalism. Stanford, CA: Stanford Univ. Press.

Howard-Grenville, Jennifer (2005) "Explaining Shades of Green: Why do Companies Act Differently on Similar Environmental Issues?,” Law \& Social Inquiry 30: 551-581.

Howard-Grenville, Jennifer (2006) “Inside the 'Black Box’: How Organizational Culture Informs Attention and Action on Environmental Issues," Organization \& Environment 19: 46-73.

Howard-Grenville, Jennifer (2007) Corporate Culture and Environmental Practice: Making Change at a High-Technology Manufacturer. Northampton, Mass.: Edward Elgar.

Howard-Grenville, Jennifer, and Andrew Hoffman (2003) "The Importance of Cultural Framing to the Success of Social Initiatives in Business," Academy of Management Executive 17: 7084.

Hunt, Christopher, and Ellen Auster (1990) "Proactive Environmental Management: Avoiding the Toxic Trap,” Sloan Management Review Winter: 7-18.

International Organization for Standardization (ISO) (2006) The ISO Survey -- 2005. Available at: http://www.iso.org/iso/en/iso9000-14000/pdf/survey2005.pdf (accessed September 8, 2007).

Jackson, Susan, and Jane Dutton (1988) “Discerning Threats and Opportunities," Administrative Science Quarterly 33: 370-387.

Johnston, Jason Scott 2006. “The Promise and Limits of Voluntary Management-Based Regulatory Reform: An Analysis of EPA's Strategic Goals Program.” In Leveraging the Private Sector: Management-Based Strategies for Improving Environmental Performance, edited by C. Coglianese and J. Nash. Washington, DC: Resources for the Future Press.

Khanna, Madhu (2001) “Non-mandatory Approaches to Environmental Protection,” Journal of Economic Surveys 15: 291-324.

Khanna, Madhu, and Lisa Damon (1999) "EPA's Voluntary 33/50 Program: Impact on Toxic Releases and Economic Performance of Firms," Journal of Environmental Economics and Management 37: 1-25.

King, Andrew, and Michael Lenox (2000) "Industry Self-Regulation without Sanctions: The Chemical Industry’s Responsible Care Program,” Academy of Management Journal 43: 698716.

King, Gary, Robert Keohane, and Sidney Verba (1994) Designing Social Inquiry: Scientific Inference in Qualitative Research. Princeton: Princeton Univ. Press.

Kleindorfer, Paul (2006) "The Risk Management Program Rule and Management-Based Regulation.” In Leveraging the Private Sector: Management-based Strategies for Improving 
Environmental Performance, edited by C. Coglianese and J. Nash. Washington, DC: Resources for the Future Press.

Krackhardt, David, and Jeffrey Hanson (1993) "Informal Networks: The Company Behind the Chart,” Harvard Business Review 71: 104-111.

Lawrence, Paul, and Jay Lorsch (1967) "Differentiation and Integration in Complex Organizations,” Administrative Science Quarterly 12: 1-47.

Lyles, Marjorie and Ian Mitroff (1980) “Organizational Problem Formulation: An Empirical Study,” Administrative Science Quarterly 25: 102-120.

Lyon, Thomas, and John Maxwell (2002) “'Voluntary’ Approaches to Environmental Regulation.” In Economic Institutions and Environmental Policy, edited by M. Franzini and A. Nicita. Chippenham, UK: Ashgate Studies in Environmental Policy and Practice.

Maxwell, John, and Christopher Decker (1998) "Voluntary Environmental Investment and Regulatory Flexibility,” Working Paper, Department of Business Economics and Public Policy, Kelley School of Business, Indiana Univ., Bloomington.

Miles, Matthew, and Michael Huberman (1994) Qualitative Data Analysis: An Expanded Sourcebook (2nd ed.). Thousand Oaks, Calif.: Sage.

Meyerson, Debra, and Joanne Martin (1987) “Cultural Change: An Integration of Three Different Views,” Journal of Management Studies 24: 623-647.

Morrison, Catherine (1991) Managing Environmental Affairs: Corporate Practices in the US, Canada and Europe. New York: Conference Board.

Ocasio, William (1997) “Towards an Attention-Based View of the Firm,” Strategic Management Journal 18: 187-206.

Porter, Michael, and Claas Van der Linde (1995) "Green and Competitive: Ending the Stalemate,” Harvard Business Review 73: 120-134.

Potoski, Matthew, and Aseem Prakash (2002) "Protecting the Environment: Voluntary Regulations in Environmental Governance,” Policy Currents 11: 9-14.

Prakash, Aseem (2000) Greening the Firm: The Politics of Corporate Environmentalism. Cambridge: Cambridge Univ. Press.

Reinhardt, Forest (2000) Down to Earth: Applying Business Principles to Environmental Management. Boston: Harvard Univ. Press.

Roberto, Michael, Richard Bohmer, and Amy Edmondson (2006) “Facing Ambiguous Threats,” Harvard Business Review 84: 106-113. 
Roome, Nigel (1992) “Developing Environmental Management Strategies,” Business Strategy and the Environment 1: 11-23.

Russo, Michael, and Niran Harrison (2005) "Organizational Design and Environmental Performance: Clues from the Electronics Industry,” Academy of Management Journal 48: 582-593.

Schein, Edgar (1992) Organizational Culture and Leadership (2nd ed.). San Francisco: JosseyBass.

Schein, Edgar (1996) “Three Cultures of Management: The Key to Organizational Learning,” Sloan Management Review Fall: 9-20.

Schön, Donald (1983) The Reflective Practitioner. New York: Basic Books.

Segerson, Kathleen, and Thomas Miceli (1998) "Voluntary Environmental Agreements: Good or Bad News for Environmental Protection?," Journal of Environmental Economics and Management 36: 109-130.

Shapiro, Stuart (2002) "Speed Bumps and Roadblocks: Procedural Controls and Regulatory Change," Journal of Public Administration Research and Theory 1: 29-58.

Sharma, Sanjay (2000) "Managerial Interpretations and Organizational Context as Predictors of Corporate Choice of Environmental Strategy,” Academy of Management Journal 43: 681697.

Sharma, Sanjay, Amy Pablo,, and Harry Vredenburg (1999) "Corporate Environmental Responsiveness Strategies,” Journal of Applied Behavioral Sciences 35: 87-108.

Shrivastava, Paul (1995) “Ecocentric Management in a Risk Society,” Academy of Management Review 20: 118-137.

Smircich, Linda (1983) "Concepts of Culture and Organizational Analysis," Administrative Science Quarterly 28: 339-358.

Snook, Scott A. (2000) Friendly Fire: The Accidental Shootdown of U.S. Black Hawks Over Northern Iraq. Princeton, N.J.: Princeton Univ. Press.

Snyder, Mark (1974) "Self-monitoring of Expressive Behavior," Journal of Personality and Social Psychology 30: 526-537.

Swidler, Anne (1986) “Culture in Action: Symbols and Strategies,” American Sociological Review 51: 273-286.

Thomas, James, Laura Shankster, and John Mathieu (1994) "Antecedent to Organizational Issue Interpretation: The Roles of Single-level, Cross-level, and Content Cues,” Academy of Management Journal 37: 1252-1284. 
U.S. Environmental Protection Agency (EPA) (2003) Top Performers. Solid Results. Performance Track Progress Report. Available at: http://www.epa.gov/performancetrack/pt_progress_report_final.pdf (accessed September 8, 2007).

U.S. Environmental Protection Agency (EPA) (2004a) Building on the Foundation: Performance Track Second Annual Progress Report. Available at: http://www.epa.gov/performancetrack/PT_2nd_progress_rpt_FINAL.pdf (accessed September 8, 2007).

U.S. Environmental Protection Agency (EPA) (2004b) “National Environmental Performance Track Program” Federal Register 69: 21737-21754.

U.S. Environmental Protection Agency (EPA) (2005a) Performance Track Program Guide. Available at: http://www.epa.gov/performancetrack/downloads/PTprog_guide.pdf (accessed September 8, 2007).

U.S. Environmental Protection Agency (EPA) (2005b) Growth \& Renewal: Performance Track Third Annual Progress Report. Available at: http://www.epa.gov/performancetrack/downloads/PT_3rd_ProgRpt.pdf (accessed September 8, 2007).

U.S. Environmental Protection Agency (EPA) (2006) Leading Change. Performance Track Fourth Annual Progress Report. Available at: http://www.epa.gov/performancetrack/downloads/PT_4th_Progress_Report.pdf (accessed September 8, 2007).

U.S. Environmental Protection Agency (EPA) (2007) National Environmental Performance Track -- Members. Available at: https://yosemite.epa.gov/opei/ptrack.nsf//faMembers?readform (accessed September 8, 2007).

Vandenbergh, Michael (2003) "Beyond Elegance: A Testable Typology of Social Norms in Corporate Environmental Compliance,” Stanford Environmental Law Journal 22: 55-144

Van Maanen, John, and Steven Barley (1984) "Occupational Communities: Culture and Control in Organizations,” Research in Organizational Behavior 6: 287-365.

Vaughn, Diane (1996) The Challenger Launch Decision: Risky Technology, Culture, and Deviance at NASA. Chicago: Univ. of Chicago Press.

Vogel, David (2005) The Market for Virtue: The Potential and Limits of Corporate Social Responsibility. Washington, DC: Brookings Institution Press. 


\section{Table 1. Organizational Factors Contributing to Problem Setting and Strategies for Action}

\begin{tabular}{|c|c|c|}
\hline Factor & Definition & Sources of evidence \\
\hline Managerial incentives & $\begin{array}{l}\text { Opportunities (or lack thereof) for managerial initiatives } \\
\text { and actions, stemming from the structure, rules, and } \\
\text { routines of the organization and the informal patterns of } \\
\text { influence and control. }\end{array}$ & $\begin{array}{l}\text { - Formal reporting structure } \\
\text { - Patterns of information flow } \\
\text { - Approval procedures } \\
\text { - Compensation schemes }\end{array}$ \\
\hline Organizational culture & $\begin{array}{l}\text { System of meanings and norms that shape daily action and } \\
\text { interactions within a company, i.e., "the way things are } \\
\text { done." }\end{array}$ & $\begin{array}{l}\text { - Tacit norms of behavior } \\
\text { - Observed, repeated patterns of } \\
\text { interaction } \\
\text { - Rules revealed through actions that } \\
\text { breach them }\end{array}$ \\
\hline Organizational identity & $\begin{array}{l}\text { Members' perceptions of what is central, enduring and } \\
\text { distinctive about their company, i.e., "what kind of } \\
\text { company we are.” }\end{array}$ & $\begin{array}{l}\text { - Members' statements of what the } \\
\text { organization "is about" } \\
\text { - Reflections of what is threatened when } \\
\text { outsiders are critical of the organization }\end{array}$ \\
\hline $\begin{array}{l}\text { Organizational self } \\
\text { monitoring }\end{array}$ & $\begin{array}{l}\text { Choices about how an organization portrays its actions to } \\
\text { outsiders, in response to its impressions of those outsiders } \\
\text { and the value it places on adhering to socially appropriate } \\
\text { portrayals. }\end{array}$ & $\begin{array}{l}\text { - Public portrayals through media, } \\
\text { website, and community outreach } \\
\text { - Number, variety, and scope of } \\
\text { partnerships or associations with } \\
\text { external groups }\end{array}$ \\
\hline $\begin{array}{l}\text { Personal commitments } \\
\text { and affiliations }\end{array}$ & $\begin{array}{l}\text { Individual members' professional experiences, education } \\
\text { and training, and personal interests and values that } \\
\text { influence their awareness of and perspectives on } \\
\text { environmental issues. }\end{array}$ & $\begin{array}{l}\text { - Professional backgrounds } \\
\text { - Memberships in other business or } \\
\text { environmental organizations } \\
\text { - Stated values }\end{array}$ \\
\hline
\end{tabular}


Table 2. NEPT and Matched Facilities: Comparison of Size and Community Demographics

\begin{tabular}{|c|c|c|c|}
\hline $\begin{array}{c}\text { Facility } \\
\text { Pseudonym }\end{array}$ & $\begin{array}{c}\text { Number of } \\
\text { Employees }\end{array}$ & $\begin{array}{c}\text { Sales } \\
\text { (\$ in millions) }\end{array}$ & $\begin{array}{c}\text { \% Community } \\
\text { Designated } \\
\text { "Urban” * }\end{array}$ \\
\hline Aero Inc. & 500 & 75 & 48 \\
Matched Facility & 700 & 60 & 82 \\
\hline Chem Co. & 750 & 858 & 98 \\
Matched Facility & 620 & 200 & 100 \\
\hline Glue Co. & 63 & 33 & 99 \\
Matched Facility & 100 & 33 & 100 \\
\hline Rubber Inc. & 900 & 50 & 99 \\
Matched Facility & 700 & 50 & 72 \\
\hline Tech Co. & 6,000 & 1,000 & 99 \\
Matched Facility & 8,000 & 5,000 & 98 \\
\hline
\end{tabular}

* As a rough indicator of community characteristics, we calculated the percentage of each facility's zip code designated as “urban” according to the U.S. Census Bureau. 
Table 3. NEPT and Matched Facilities: Comparison of Compliance, TRI Releases, and Permitting

\begin{tabular}{|c|c|c|c|c|c|}
\hline Facility Pseudonym & $\begin{array}{c}\text { Subject to Recent } \\
\text { Enforcement Action }\end{array}$ & $\begin{array}{c}\text { Trend in TRI } \\
\text { Releases }\end{array}$ & $\begin{array}{c}\text { Hazardous Waste } \\
\text { Permit }\end{array}$ & $\begin{array}{c}\text { Air Permits } \\
\text { Inspection }\end{array}$ & $\begin{array}{c}\text { No } \\
\text { No }\end{array}$ \\
\hline Aero Inc. & No & Down & Yes & Yo \\
Matched Facility & No & Down & Yes & No & Yes \\
\hline Chem Co. & No & Down & Yes & Yes \\
Matched Facility & No & Down & Yes & Yes \\
\hline Glue Co. & No & Down & Yes & Yes & Yes \\
Matched Facility & No & Up & Yes & Yes \\
Rubber Inc. & No & Down & Yes & Yes \\
Matched Facility & No & Down & Yes & Yes \\
\hline Tech Co. & No & Down & Yes & \\
\hline
\end{tabular}


Figure 1: The Construction of the License to Operate

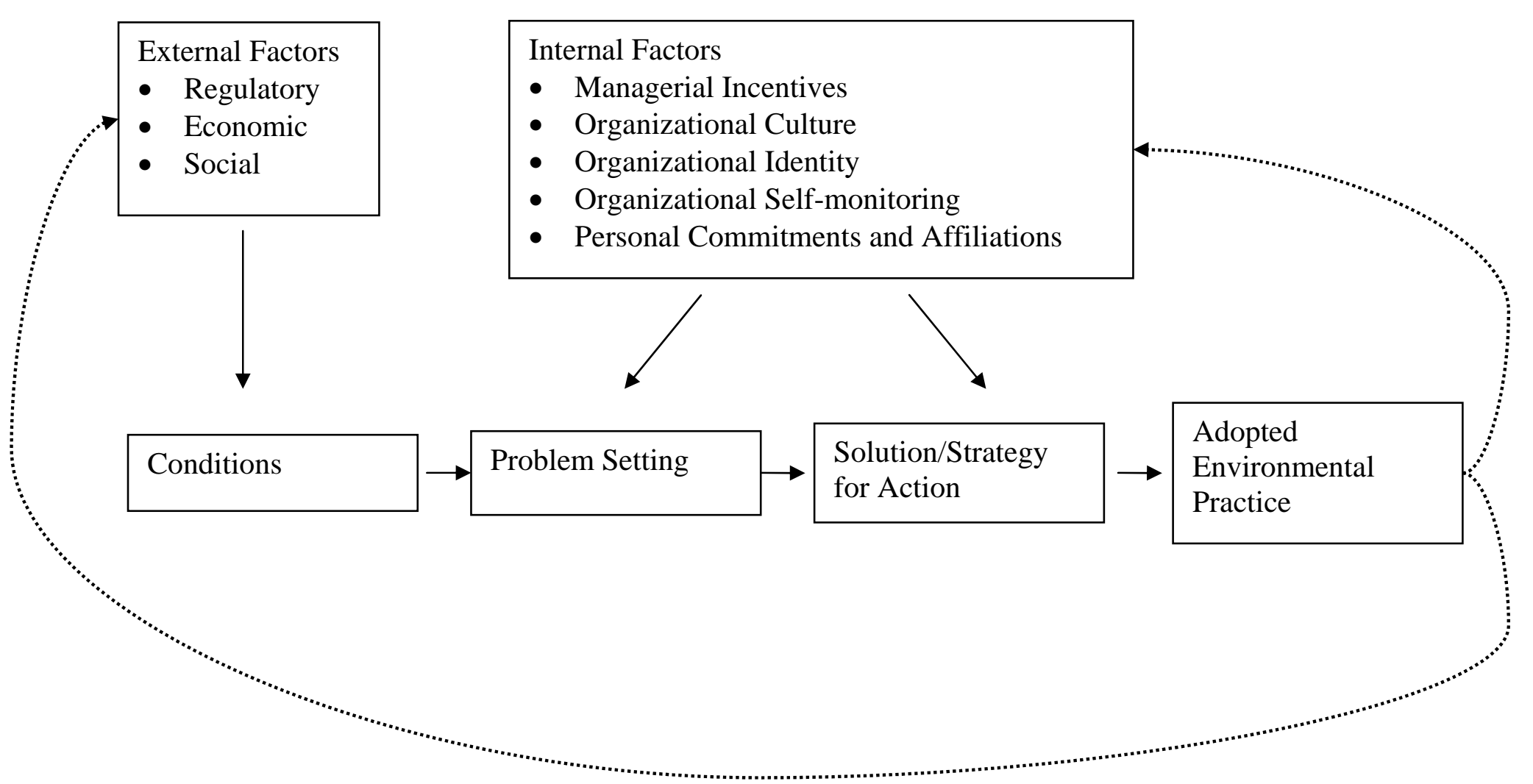

